\title{
Portal Infusion of Low Dosage Endotoxin: A Model Simulating Translocation of Ruminal Endotoxin in Cattle
}

Translocation of bacteria and endotoxin from the gastro-intestinal tract to the portal blood is described to occur in healthy humans and animals, and is probably facilitated by ruminal epithelium damage in cattle (Berg 1992). Controversy exists regarding the possible role of endotoxin in the pathogenesis of ruminal acidosis. Systemic disease during ruminal acidosis is clinically characterized by forestomach stasis, anorexia, depression, tachycardia, tachypnea and fever. It has been shown that blood concentrations of arachidonic acid metabolites increase during ruminal acidosis, which may explain many of these clinical signs (Andersen et al. 1994). At the same time, we found that only few cows with experimentally induced rumen acidosis had endotoxin in the systemic blood (Andersen et al. 1990, 1994), while other authors describe systemic endotoxaemia as an occasional finding in similar or milder cases of grain-engorgement (Boosman et al. 1990, Aiumlamai et al. 1992). Arachidonic acid metabolites are readily produced in the presence of endotoxin, but might also be expected to be produced during a chemical inflammation process of ruminal epithelium, damaged by a low $\mathrm{pH}$ and high osmolar concentration. The purpose of the present study was to evaluate the role of low grade portal endotoxaemia for pre-hepatic release of inflammatory mediators 6-ketoprostaglandin $F_{1 \alpha}$ (6-keto-PGF) and thromboxane $B_{2}$
(TXB) and the relation to systemic disease. Four healthy cows were surgically equipped with chronic catheters in the portal vein, in a mesenteric vein $20 \mathrm{~cm}$ distally to portae hepatis and in a hepatic vein. After recovery, the cows received at maximum 3 different treatments at monthly intervals in a randomized design. Treatments were saline solution infused into the mesenteric vein at $2.5 \mu \mathrm{L} / \mathrm{kg}$ body weight per min (control), Escherichia coli endotoxin (055:B5 Westphals extraction, Sigma) at $0.025,0.25$ and $2.5 \mathrm{ng} / \mathrm{kg}$ body weight per min (Model I, Model II and Model III, respectively, Table 1). Infusions were continued for $180 \mathrm{~min}$, or until respiratory distress (respiration rate $>40$ per $\mathrm{min}$ ) occurred. One $\mathrm{h}$ before a session, a jugular catheter was inserted, and blood samples were collected from the portal, hepatic and jugular vein for determination of clinical-chemical parameters (acid-base balance, packed cell volume (PCV), leukocyte and thrombocyte counts), endotoxin, TXB and 6-keto-PGF. Methods are described elsewhere (Andersen et al. 1994). After initiation of the experimental infusion, sampling was continued for $330 \mathrm{~min}$ at intervals of $30 \mathrm{~min}$. Clinical parameters (rectal temperature, pulse and respiratory rates and ruminal movements) were determined hourly.

The results of the experiment are given in Figs. $1 \& 2$ (Leukocyte and thrombocyte 
Tabel 1. Occurrence of peak values (min after initiation of pre-hepatic endotoxın administration) and relative peak values (\% of base line values) for $\mathrm{TXB}_{2}$ and 6-keto-PGF.

\begin{tabular}{|c|c|c|c|c|c|c|c|}
\hline & & $\begin{array}{l}\text { Endotoxin infusion } \\
\text { rate ng } / \mathrm{kg} / \mathrm{min}\end{array}$ & $\begin{array}{l}\text { Cumulative } \\
\text { dosage ng/kg }\end{array}$ & $\begin{array}{l}\mathrm{TXB}_{2} \text { peak } \\
\text { occurence, minutes }\end{array}$ & $\begin{array}{l}\mathrm{TXB}_{2} \text { peak size, } \\
\% \text { of baseline value }\end{array}$ & $\begin{array}{l}\text { 6-keto-PGF peak } \\
\text { occurrence, minutes }\end{array}$ & $\begin{array}{l}\text { 6-keto-PGF peak size } \\
\% \text { of baseline value }\end{array}$ \\
\hline \multirow{4}{*}{ Model I } & \multirow{4}{*}{$(n=3)$} & \multirow{4}{*}{0.025} & 4.5 & 180 & 283 & - & - \\
\hline & & & 4.5 & 180 & 256 & - & - \\
\hline & & & 4.5 & 180 & 312 & - & - \\
\hline & & & 22.5 & 60 & 2222 & 180 & 131 \\
\hline \multirow[t]{2}{*}{ Model II } & \multirow[t]{2}{*}{$(n=3)$} & \multirow[t]{2}{*}{0.25} & 22.5 & 120 & 556 & 180 & 122 \\
\hline & & & 45 & 150 & 228 & - & - \\
\hline Model III & $(\mathrm{n}=1)$ & 2.5 & 225 & 30 & 1067 & 180 & 162 \\
\hline Control & $(n=2)$ & 0 & 0 & - & - & - & - \\
\hline
\end{tabular}

-: no peak occurred.

counts, respectively) and in Table 1 (TXB and 6-keto-PGF). The response to the endotoxin infusions showed marked differences between models and between individuals. Administration of endotoxin at $0.025 \mathrm{ng} / \mathrm{kg} / \mathrm{min}$ (Model I) did not cause clinical effects or alteration on leukocyte and thrombocyte counts. However, TXB synthesis was enhanced and peaked when infusion was stopped. The concentration rapidly declined and was at baseline level $60 \mathrm{~min}$ later. Increased concentrations of 6-keto-PGF was not observed. When endotoxin was infused at $0.25 \mathrm{ng} / \mathrm{kg} / \mathrm{min}$ (Model II), 2 of the cows developed transient respiratory distress and rumen atony, and the infusions were stopped after $90 \mathrm{~min}$. These cows developed leukopenia in various degrees after $60 \mathrm{~min}$ and a slight thrombopenia was noted after $150 \mathrm{~min}$. TXB2 synthesis was enhanced, the peaks were higher and occurred earlier, when compared to the cows in Model I. Enhanced synthesis of 6-keto-PGF was observed only in the 2 cows, who showed the earliest and strongest TXB response. Administration of endotoxin at 2.5 $\mathrm{ng} / \mathrm{kg} / \mathrm{min}$ caused clinical signs as depression, tremor, fever, respiratory distress and rumen atony. A marked and rapid onset of leukopenia and thrombopenia was observed in this case. The TXB and 6-keto-PGF concentrations peaked at 30 and $180 \mathrm{~min}$, respectively. These findings confirm the observations of Eades (1993), who concluded that the biochemical pathways for thromboxane are very sensitive to the effects of endotoxin. The concentrations of 6-keto-PGF was significantly lower in the hepatic blood compared to portal blood concentrations, suggesting a clearing of this mediator in the liver. The TXB concentrations showed a similar, but less clear, tendency. There was no difference in leukocyte and thrombocyte counts between the different vessels. The present results indicate that the number of leukocytes is more sensitive to low dosage endotoxin, than the number of thrombocytes.

Endotoxins injected intravenously in healthy cows disappear rapidly from the blood, even when injected in doses at $25 \mu \mathrm{g} / \mathrm{kg}$ body weight (Andersen et al. 1988), and as expected endotoxin was not detected in any of the cows in this study. If the portal blood flow was e.g. $25 \mathrm{l} / \mathrm{min}$, the concentration of endotoxin in the portal vein theoretically would be below or 


\section{Leukocytes $10^{\circ} / \mathrm{L}$}

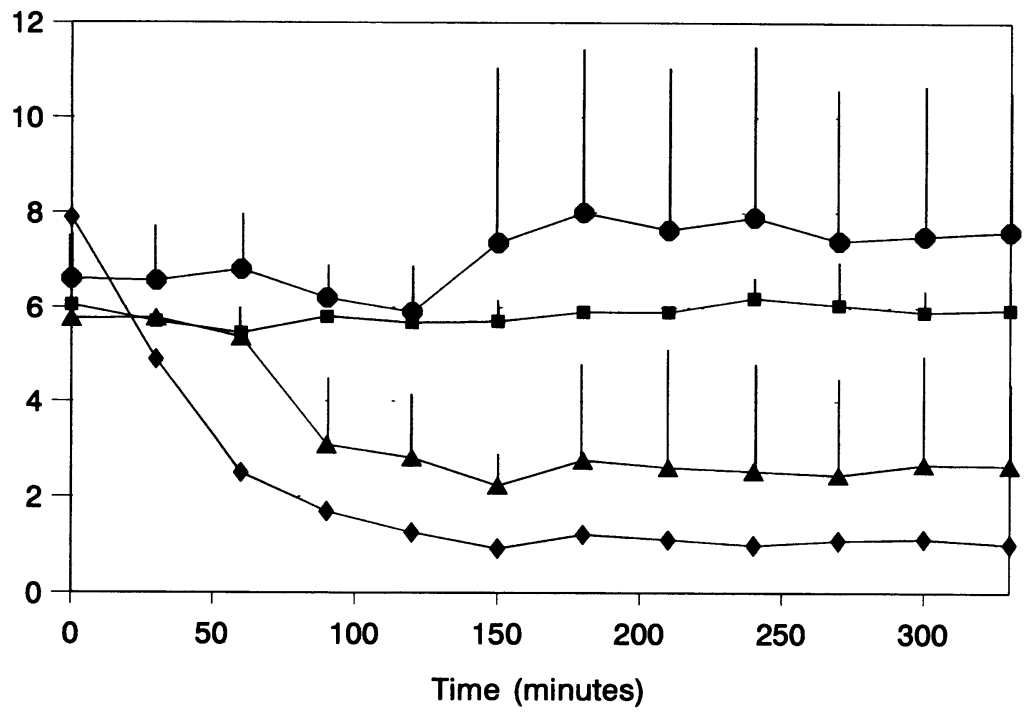

Figure 1. Blood leukocyte count before, during and after infusion of saline $(\square)$ or endotoxın at $0.025(\bullet), 0.25$ $(\Delta)$ and $2.5(\diamond) \mathrm{ng} / \mathrm{kg}$ body weight $/ \mathrm{min}$. Bars indicate S.D.

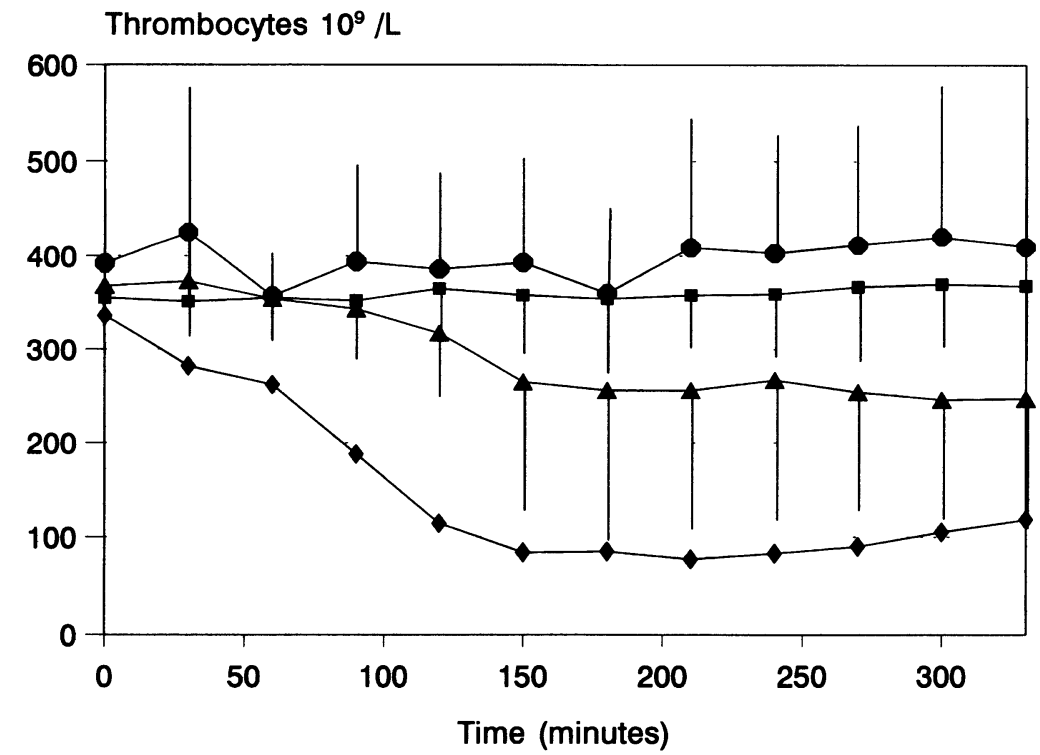

Figure 2. Blood thrombocyte count before, during and after infusion of saline ( $\square)$ or endotoxin at $0.025(\bullet)$, $0.25(\Delta)$ and $2.5(\diamond) \mathrm{ng} / \mathrm{kg}$ body weight $/ \mathrm{min}$. Bars indicate S.D. 
close to the detection limit of the Limulus Amoebocyte Lysate (LAL) assay on 3 pg Escherichia coli endotoxin $055: \mathrm{B} 5 / \mathrm{ml}$ in water, which is much lower in whole blood. These results show, that endotoxaemia, as defined by positive LAL results, not necessarily is related to the clinical signs on endotoxicosis. This is in accordance with endotoxin investigations in cases of ruminal acidosis, where absence of endotoxaemia is an occasional finding, despite signs of endotoxicosis (Andersen \& Jarløv 1990, Aiumlamai et al. 1992, Andersen et al. 1994). It is also interesting that the cows in Model I seemed to be unaffected by the endotoxin infusion, but still had increased concentrations of TXB.

\section{Acknowledgement}

This study is supported by grants from the Danish Agricultural and Veterinary Research Council (134216-1).

P. Haubro Andersen, Department of Clnical Stud1es, Surgery, Royal Veterinary and Agricultural University, Frederiksberg, Denmark.

\section{References}

Alumlamal S. Kindahl H, Fredriksson G, Edqvist $L-E$, Kulander $L$, Eriksson $O$ : The role of endotoxins in induced rumınal acidosis in calves. Acta vet. scand. 1992, 33, 117-127.

Andersen $P H, J a r l \phi v N$ : Investigation of the possible role of endotoxin, TXA2, PGI2 and PGE2 in experımentally induced rumen acidosis in cattle. Acta vet. scand. 1990, 31, 27-38.

Andersen PH, Jarl $\varnothing v$ N, Hesselholt M: Pathophysiology of experımental bovine endotoxicosis I: Endotoxin in vivo clearance in healthy and hepatic lipıdotic cattle. Proceedings XVth World Buiatrics Congress 1988, p. 1410-1415.

Andersen PH, Hesselholt M, Jarl $\varnothing \nu$ N: Endotoxin and arachidonic acid metabolites in portal, hepatic and arterial blood of cattle with acute ruminal acıdosis. Submitted Acta vet. scand. 1994

Berg, $R D$ : Translocation of enteric bacteria in health and disease. Curr. Stud. Hematol. Blood Transfus. 1992, 59, 44-65.

Boosman R, Mutsaers CWAAM, Klarenbeek A: Experımental bovine ruminal acidosis associated with endotoxaemia and lamınitis. Bovine Laminitis. Histopathologic and arteriographic aspects and its relation to endotoxaemia. Thesis, University of Utrecht, The Netherlands. 1990, p. 78-93.

Eades $S C$ : Endotoxemia in dairy cattle: Role of eicosanoids in retıculorumen stasis. J.Dairy Sci. 1993, $76,414-420$.

(Recelved January 27, 1994; accepted February 28, 1994).

Reprints may be requested from: P. Haubro Andersen, Department of Clınical Studies, Surgery, Royal Veterinary and Agricultural University, Bulowsvej 13, DK-1870 Frederiksberg C, Denmark. 

